\title{
FATORES MOTIVACIONAIS EM UMA EMPRESA DO SEGMENTO COMERCIAL NA CIDADE DE RECIFE
}

\author{
https://dx.doi.org/10.48097/2674-8673.2022n6p07
}

\author{
Natália Batista Lins ${ }^{1}$ \\ Nayana Júlia dos Santos Bandeira² \\ João Biron de Oliveira Filho ${ }^{3}$ \\ Eronildo Ferreira do Carmo ${ }^{4}$
}

\section{RESUMO}

Este trabalho trata de algumas variáveis inerentes à motivação dos indivíduos no ambiente de trabalho e do incentivo aos colaboradores no processo produtivo que conduz a resultados positivos. Mediante pesquisa realizada na empresa Padeirão Food Service, localizada na cidade de Recife-PE, pretende-se mostrar a importância da criação de um ambiente propício à motivação que gere, consequentemente, inovação nas organizações. Em relação à apresentação dos resultados da pesquisa, optou-se por dar maior ênfase à importância da motivação dentro da empresa como fonte de inovação, uma vez que os fatos aqui relatados mostram efetivamente a inexistência de um processo motivacional que incentive os colaboradores da organização.

Palavras-chave: Clima Organizacional. Motivação. Níveis Motivacionais.

Data de submissão: 12/08/2021

Data de aprovação: 14/09/2021

\begin{abstract}
This work deals with some variables inherent to the motivation of individuals in the work environment and the encouragement of employees in the production process that leads to positive results. Through research carried out at Padeirão Food Service, located in the city of Recife-PE, it is intended to show the importance of creating an environment conducive to motivation that generates, consequently, innovation in organizations. Regarding the presentation of the research results, it was decided to give greater emphasis to the importance of motivation within the company as a source of innovation, since the facts reported here effectively show the inexistence of a motivational process that encourages the organization's employees.
\end{abstract}

\footnotetext{
${ }^{1}$ Concluinte do Curso de Pós-graduação em Psicologia Organizacional e do Trabalho da FMGR. E-mail: natalia-lins@live.com

${ }^{2}$ Concluinte do Curso de Pós-graduação em Psicologia Organizacional e do Trabalho da FMGR. E-mail: nayana.julia12@gmail.com

${ }^{3}$ Docente orientador do Curso de Pós-graduação em Gestão da Psicologia Organizacional e do Trabalho da FMGR. E-mail: joaobiron@gmail.com

${ }^{4}$ Docente coorientador do Curso de Pós-graduação em Gestão da Psicologia Organizacional e do Trabalho da FMGR. E-mail: proferon100@gmail.com
} 
Keywords: Organizational Climate. Motivation. Motivational Levels.

\section{INTRODUÇÃO}

A motivação é um dos principais fatores para o comportamento das pessoas em uma empresa. Caso elas não estejam com boa autoestima nada irá fazer com que desempenhem suas atividades de forma eficaz. Em todas as empresas há gerentes, chefes, gestores. Apesar do nome, todos têm o papel de ser líder, ou seja, orientar as pessoas que estão ao seu redor para que elas busquem o melhor resultado em um lugar onde há várias incertezas.

Organização e maximização de lucros são evidentes sobre quaisquer outros objetivos da empresa e muitos defendem o uso de formas de controlar os subalternos a fim de predeterminar o nível de produtividade. Entende-se que a melhor forma de incentivar a motivação é substituir a punição pela remuneração. Dessa maneira, os trabalhadores escolheriam o trabalho pela perspectiva de remuneração e não pelo cargo ou tipo de trabalho. A abordagem dada à ação de equilíbrio pelo bom desempenho torna-se tão intensa que a satisfação a ser conquistada pelo trabalho passa a ser a própria motivação para executá-lo. (FERREIRA, 2001).

Muitos teóricos sugerem um sistema de recompensa/punição, entretanto, nesse ambiente de trabalho, com produtividade máxima, os colaboradores perceberam que estavam correndo risco na sua própria segurança no trabalho. Receberiam maior remuneração, porém haveria um número bem mais reduzido de funcionários para a mesma produtividade.

Conforme cita Ferreira (2001), outra proposta é adotar e defender uma postura administrativa que visa à importância da pessoa na sua plenitude. A melhor forma de motivar os trabalhadores seria dando importância às características sociais dos mesmos. As organizações começariam a mostrar aos funcionários a sua importância pessoal no trabalho. Dessa forma, eles iriam se sentir úteis e também motivados. Essa estratégia visa avivar os valores pessoais e satisfazer as necessidades sociais.

Outra visão de trabalho é quanto à necessidade de satisfazer os desejos naturais dos colaboradores, visando à integração em determinado grupo social sem que fosse jamais esquecido o valor individual. Essas necessidades foram consideradas tão importantes que substituíram com vantagens as recompensas em pecúnia. A manipulação das pessoas continuou, embora de um modo bem diferente. Afinal, caberia aos supervisores demonstrar sua preocupação e simpatia para com as necessidades, desejos e problemas dos seus subordinados.

Os canais de comunicação, tanto no sentido ascendente como descendente, passaram a 
ser valorizados. A partir desse novo modelo de compreensão do ser humano em situações de trabalho, os funcionários deveriam conhecer tudo aquilo que diz respeito à organização, tendo abertura para expor suas ideias para com as estratégias produtivas, de acordo com as diretrizes administrativas da organização. Dessa forma, consequentemente, os esforços e recompensas deixariam de ser individuais e passariam a ser grupais.

Esses trabalhadores são vistos como pessoas que possuem diferentes habilidades e talentos que são próprios, tendo condições de contribuir da sua maneira para a consecução dos objetivos organizacionais, cabendo à administração buscar meios para desbloquear a saída de tais recursos para que se transformem em ações eficazes e produtivas.

Reconhece-se que cada um já traz de alguma forma dentro de si suas próprias motivações. As organizações devem ser capazes de não sufocar as forças motivacionais inerentes às próprias pessoas de tal forma que elas não percam sua sinergia motivacional.

Esse trabalho tem a finalidade de avaliar os fatores motivacionais, tais como remuneração e benefícios, desempenhados na empresa Padeirão Food Service, buscando saber como a organização está segurando o seu capital humano.

\section{REFERENCIAL TEÓRICO}

\section{Histórico e Conceito de Motivação}

A motivação procura explicar o porquê do comportamento das pessoas e de acordo com Maximiano (2010) indica as causas ou motivos que produzem determinado comportamento, seja ele qual for, e que está baseada em três propriedades: direção (para onde a motivação leva o comportamento), intensidade (amplitude da motivação) e a permanência (duração da motivação).

A Administração Científica baseava-se na concepção do homo economicus, segundo o qual o comportamento do homem é motivado exclusivamente pela busca do dinheiro e pelas recompensas salariais e materiais do trabalho, onde ele pretende maximizar seus rendimentos e cujos princípios se basearam na estrutura formal e nos processos das organizações.

Toda a abordagem clássica da administração se baseava nessa estreita teoria da motivação. O experimento de Hawthorne foi um dos eventos mais importantes na história do enfoque comportamental na administração, realizado entre 1927 e 1933, e depois fez parte de um programa mais amplo, orientado pelo professor Elton Mayo, que durou até 1947. Elton Mayo (1933, apud MAXIMIANO, 2010) e sua equipe demonstraram uma teoria da motivação contrária à do homo economicus, onde o ser humano é motivado, não por estímulos 
salariais e econômicos, mas por recompensas sociais e simbólicas, pois a recompensa salarial não é o único fator decisivo que motiva o trabalhador dentro da organização. São muitos os meios de reconhecer e valorizar o comportamento positivo das pessoas, oferecendo desafios e desenvolvendo programas de reconhecimento instantâneo, como por exemplo, brindes, um dia de folga, um mês de estacionamento grátis, entre outros.

\section{Motivação no Ambiente Organizacional}

Nos dias atuais o tema "motivação" tem sido cada vez mais discutido, pois as empresas têm mostrado cada vez mais a necessidade nessa questão. Isso se deve a esse mundo cada vez mais agitado, consequência de um capitalismo cada vez mais severo. Essa concorrência está deixando as pessoas ainda mais assustadas, pois o mercado de trabalho vem oferecendo menos oportunidades. A situação se complica quando o candidato não apresenta uma qualificação compatível a uma função almejada.

$\mathrm{Na}$ busca de tentar entender um pouco sobre o assunto, é importante saber o conceito dessa palavra que tanto se fala, mas poucos a valorizam. Não há apenas um único nome que defina motivação, pois sua definição é muito complexa. A própria denominação sugere ser um motivo para uma ação. Motivo este que está relacionado ao aspecto psicológico de cada individuo. Alguns autores a definem como causa de um comportamento ou conjunto de forças internas que orientam a conduta de um indivíduo para determinado objetivo ou um processo psicológico que leva uma pessoa a fazer esforços para obter determinado resultado.

A motivação humana é complexa e por isso tem se tornado uma área de bastante preocupação na teoria e práticas administrativa. Essa preocupação consiste na busca de uma relação mais satisfatória entre o colaborador e a organização. A motivação é uma força interior propulsora, de importância decisiva no desenvolvimento do ser humano. Assim como na aprendizagem em geral, o ato de aprender algo é ativo e não passivo.

Baseado nos conceitos sobre motivação que foram relacionados nesse estudo, definimos motivação como fatores impulsionadores que nos levam a determinadas ações. Na perspectiva organizacional, motivar é incentivar pessoas e equipes a trabalhar da melhor maneira possível através da construção de um ambiente favorável ao desempenho de suas aptidões. (CHIAVENATO, 2004).

No decorrer desse estudo são apresentadas diversas teorias de diferentes autores, as quais apontam diversos fatores que podem os motivar. Entende-se que nenhum fator por si só é capaz de motivar totalmente o individuo, principalmente porque os motivos humanos variam de pessoa para pessoa, e até mesmo de um momento para outro da mesma pessoa. Sendo 
assim uma tarefa difícil, pois o comportamento é extremamente complexo, devido às diferenças individuais e devido ao fato de as pessoas mudarem continuamente.

Observando a complexidade e importância da motivação nas organizações atual e devido a sua influência nos resultados os executivos e chefes gostariam de ver seus funcionários motivados e integrados com os objetivos da empresa de forma a atingir o máximo de produtividade. Os indivíduos se tornam um meio para a busca dos fins definidos pela organização devido ao uso de padrões organizacionais de motivação da mesma. Afinal, um profissional motivado produz muito mais. (CHIAVENATO, 2004).

\section{Níveis de Motivação}

Existem três níveis de motivação para cada indivíduo:

1) Nível semântico (os significados)

O que motiva o indivíduo é apenas aquilo que tem para ele algum significado pessoal, seja qual for o significado que esse indivíduo lhe atribui. O indivíduo move-se pelos instintos que nascem da sua individual valoração positiva ou negativa, procurando os objetivos aos quais agregou à primeira e distanciando-se dos objetivos aos quais agregou à segunda. $\mathrm{O}$ indivíduo diz-se centrado em si mesmo, isto é, na sua única e própria esfera de valorações.

\section{2) Nível cognitivo (da aprendizagem)}

Para um indivíduo plenamente receptivo a todos os estímulos que capta do seu ambiente (exterior e interior), há um descentramento da sua rede de entidade valorativas. A valoração já não reside em si, mas apenas no prazer que pode extrair da aprendizagem do que lhe é exterior e do que lhe é interior. Não existe um objeto que lhe seja desinteressante. Tudo é considerado interessante e passível de ser conhecido por vontade própria. Estes indivíduos podem experimentar um sentimento de ligação mística com o universo de estímulos que se lhes apresenta. Porém, podem também sofrer de uma incapacidade na definição precisa e concreta de um único objetivo ou meta face à sua valoração. $\mathrm{O}$ seu pensamento divergente $\mathrm{e}$ extremamente fluido pode levar a uma dispersão da sua atenção e à incapacidade de realização concreta de qualquer tarefa a que se proponham.

\section{3) Nível existencial (do ato)}

Para um indivíduo ultrapassar esse primeiro momento de dispersão da sua atenção mediante todos os estímulos que existem no meio, existe a consciência de que não é possível 
conhecer todos os estímulos que se nos apresentam. As causas são óbvias: a quantidade de estímulos recebida por instante é muito superior à capacidade perceptiva humana. Interpretar cada um desses estímulos requer grandes intervalos de tempo, e, portanto, elaborar respostas a cada um desses estímulos também não é humanamente possível. A vida humana é limitada pelo nascimento e morte, sendo demasiado pequena para receber, interpretar e responder a todos os estímulos. Para o indivíduo que chega a esta inevitável conclusão, só é possível um caminho: dentre todos os estímulos existentes, escolher interpretar e responder apenas àqueles que permitem um maior e mais rápido desenvolvimento da sua personalidade.

Hoje em dia, a grande maioria das pessoas não passa do nível semântico, o mais centrado de todos. Daí decorre que a vida, atualmente, seja, sobretudo, uma luta pela sobrevivência. Para as pessoas que atingiram o nível cognitivo, a vida não é nada fácil, dado que a maioria das pessoas não passa do nível semântico e, portanto, se atropelam mutuamente para satisfazer os seus instintos. Estima-se que a maior parte das pessoas que reside no nível cognitivo não sobreviva facilmente, sendo selecionadas negativamente. Tanto maior é esta seleção negativa quando maior e mais completa for a capacidade perceptiva da pessoa, isto é, quanto maior for a sua inteligência. Daí decorre que grande parte das pessoas mais inteligentes do mundo está a ser selecionada negativamente. Em raríssimos casos, existe uma pessoa que passa para o nível existencial.

\section{Fatores Motivacionais Predominantes na Empresa Padeirão Food Service}

As organizações e o trabalho estão incluídos na vida dos seres humanos desde a sua criação. Lidar com pessoas nas organizações tem sido uma responsabilidade que, atualmente, se reveste de uma complexidade muito maior do que há poucos anos atrás. De alguma forma, todos estamos ligados a uma organização de forma direta ou indireta. E se por algum motivo não estão desempenhando o seu trabalho da melhor maneira possível cabe aos profissionais da área observar o que está acontecendo e buscar soluções adequadas para resolver.

Para Lacombe (2005), as pessoas são os atores das organizações. São elas que tomam as decisões em nome das melhorias desejadas. São também agentes econômicos que têm como objetivo maximizar sua satisfação. Portanto, as atividades econômicas e administrativas são conduzidas por pessoas, que procuram satisfazer suas necessidades, desejos e até mesmo seus caprichos e, se essas pessoas não estiverem motivadas, seus resultados talvez não atinjam os objetivos desejados por todos.

Algum tempo atrás as cooperativas não se preocupavam com o relacionamento interno e externo de seus funcionários. Hoje em dia essa prática vem mudando aos poucos. As 
cooperativas passaram a perceber que o funcionário que trabalha motivado rende muito mais para a organização, portanto, com o passar dos anos alguns esforços vêm sendo feitos no sentido de melhorar a qualidade e em consequência dessa melhoria vem a satisfação das pessoas que fazem parte da organização. Um exemplo desse esforço é como as organizações estão conduzindo seu pessoal. A cada dia elas estão introduzindo em sua estrutura profissionais qualificados que, através de suas habilidades, têm a capacidade de visualizar a organização dentro de seu ambiente externo e compreender a força de seu pessoal.

Segundo Lacombe (2005), todo administrador é responsável pelo desempenho de sua equipe. Assim, da mesma forma que a equipe deve ser formada e renovada em função dos planos estratégicos da empresa, sua condução deve ter como objetivo alcançar as metas previstas naquele plano. A melhor maneira de obter resultados por meio da equipe e até mesmo superá-los é comprometê-la com as metas, desafios e, até mesmo, riscos. Toda cooperativa tem suas metas para cada período, portanto, para alcançar o desejado, toda a equipe tem que estar comprometida e motivada para desempenhar seu papel da melhor forma. Se o administrador souber cativar seu pessoal e mostrar as vantagens o desempenho das tarefas poderá ser bem melhor. Segundo Ribeiro (2006, p. 4), "administrar com as pessoas significa tocar a organização juntamente com os colaboradores e os parceiros internos que mais entendam dela e de seu futuro".

Para que uma organização obtenha um bom clima organizacional é fundamental que os donos de empresas e gerentes ouçam seus funcionários individualmente para que descubram o que lhes motiva, e também comecem a enxergar seus colaboradores não só como meio de produção, mas sim como pessoas que querem crescer junto com a organização, oferecendo condições de trabalho adequadas, dando-lhes estímulos e sempre tratando todo funcionário com muito respeito.

A motivação dentro de uma organização é essencial para que possamos sempre manter em equilíbrio tudo que nos faz obter sucesso e vitórias. Se permanecermos com funcionários motivados, podemos ter a absoluta certeza que, consequentemente, nossos clientes serão reflexos de nossos funcionários, pois estarão adquirindo toda a motivação que temos dentro de nossa empresa.

É necessário que o empresário enxergue em cada funcionário um ser humano como qualquer outro, cheio de sonhos e desejos de realização, para que possam além de dar-lhes estímulos motivacionais, recompensas pelo seu desempenho, tornando-os parte das empresas, mostrando o quanto são importantes para a produtividade da organização. 
Com o funcionário motivado, os empresários e gerentes podem sempre estar tranquilos em relação à importância e responsabilidade que o colaborador tem com a empresa, com a produção e com a satisfação dele em estar ali, exercendo tais tarefas.

\section{METODOLOGIA}

A pesquisa, em relação ao tema abordado, é de natureza qualitativa e quantitativa. $\mathrm{O}$ método quantitativo e a amostra da pesquisa são os dados obtidos através de um questionário específico para alcançar o resultado mais verdadeiro possível. O método quantitativo representa, em princípio, a intenção de garantir a precisão dos resultados, evitar distorções de análise e interpretação, por isso à escolha desse método. A pesquisa teve como base um estudo de caso quanto ao aspecto motivacional dos colaboradores da empresa Padeirão Food Service.

A pesquisa de campo teve como alvo os funcionários da organização citada. Cinquenta colaboradores foram entrevistados. Os dados foram coletados através de um questionário que buscou compreender os fatores motivacionais externos e internos que podem influenciar na motivação destes colaboradores. Foi aplicado diretamente e de forma aleatória um questionário que era composto de questões fechadas com múltiplas escolhas. O objetivo foi analisar a motivação e a satisfação dos cooperados a respeito de sua satisfação em vários aspectos como saúde, segurança, reconhecimento, relacionamento, entre outros.

\section{ANÁLISE E INTERPRETAÇÃO DOS DADOS}

A pesquisa foi elaborada com o objetivo de verificar como os colaboradores se sentem com relação à organização que trabalha, visando melhor compreensão sobre o assunto abordado. Ao analisar cada gráfico a seguir, a proposta é que o entendimento sobre o assunto fique mais claro e objetivo.

De acordo com os dados coletados, foi possível verificar que motivar é algo que vem de dentro. Todos têm objetivos a serem conquistados, ou seja, motivos ou razões para levantar cedo e ir trabalhar. Mas como anda o nível de motivação, de acordo com a pesquisa realizada? 
Gráfico 1 - Qual o nível de motivação para ir ao trabalho?

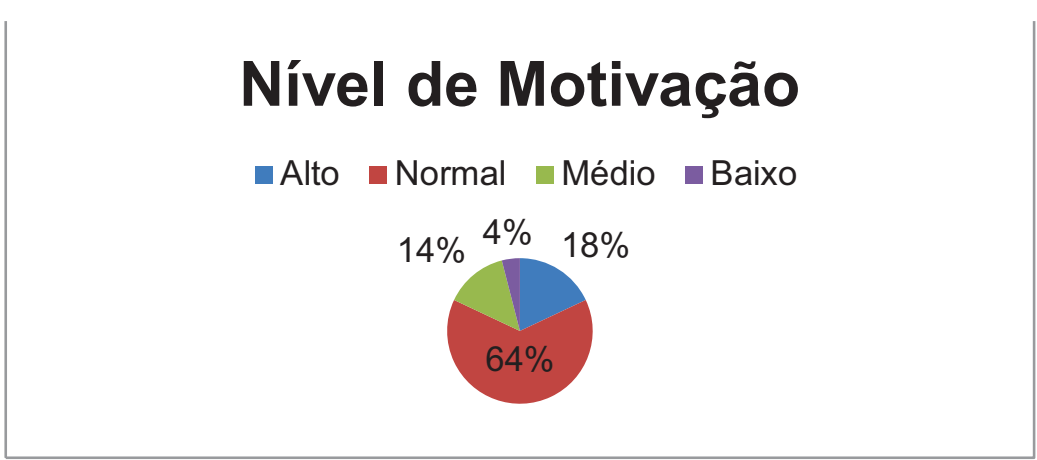

Fonte: os autores (2020)

Um líder tem habilidade de incentivar as pessoas a fazer aquilo que deve ser feito. Quanto à consideração ao colega de trabalho, os líderes precisam entender que sozinhos podem cumprir metas, mas com sua equipe motivada, ultrapassa todas as expectativas. $\mathrm{O}$ gráfico abaixo mostra o resultado da seguinte pergunta: "você recebe reconhecimento pelo seu líder quando um trabalho é bem executado"? O resultado mostra que 90\% dos colaboradores recebem reconhecimento do seu líder, o que pode ser um fator de motivação para alguns deles. Quando se é parabenizado ou reconhecido por um trabalho executado, só incentiva a melhorar.

Gráfico 2 - Você recebe reconhecimento pelo seu líder quando um trabalho é bem executado?

\section{Reconhecimento pelo seu líder}

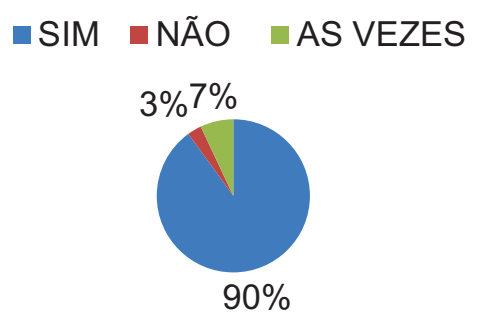

\section{Fonte: os autores}

Foi possível verificar que um dos principais fatores motivacionais nessa empresa, com cerca de 58\%, são a relações pessoais no ambiente de trabalho. As relações com os colegas e chefes são importantes, tornando um clima organizacional propício de produtividade, em que a colaboração e a solidariedade estejam presentes no cotidiano, tornando os dias mais agradáveis. 
O gráfico abaixo mostra o resultado da seguinte pergunta: "o que motiva o colaborador a trabalhar nessa organização"? A motivação dentro de uma organização é essencial para que possamos sempre manter em equilíbrio tudo que nos faz obter sucesso e vitórias.

Gráfico 3 - O que motiva o colaborador a trabalhar nesta organização?

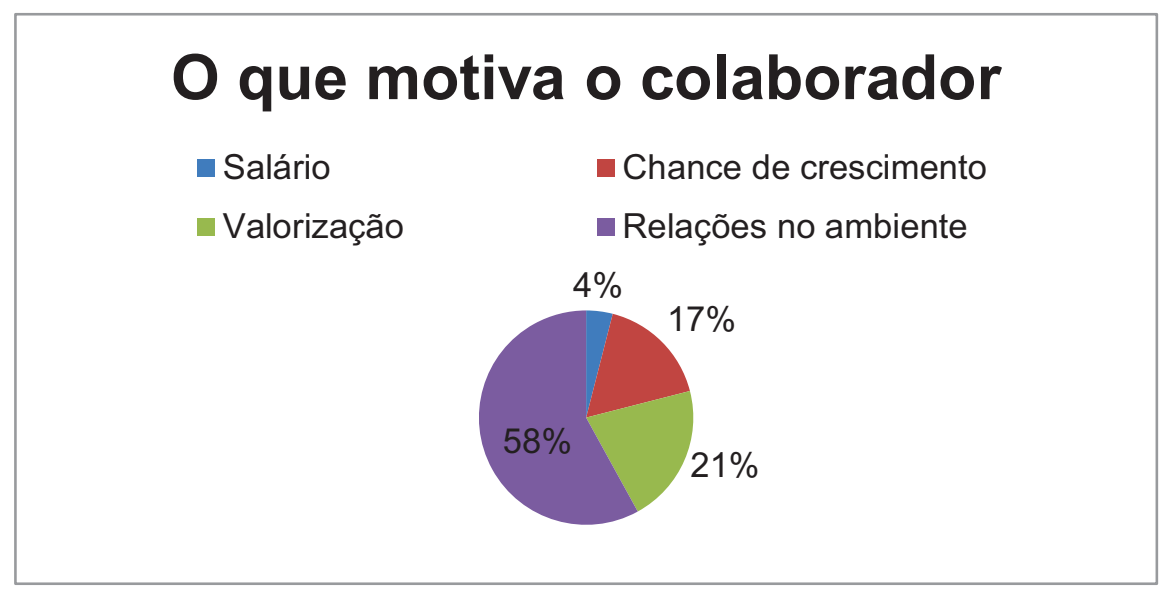

Fonte: os autores

O mercado de trabalho está alerta às mudanças e cada vez mais incentivando jovens com um futuro promissor. As organizações estão querendo esse futuro profissional em sua equipe, investindo em treinamentos e cursos. O profissional precisa ter certeza que oportunidades de crescimento irão surgir, motivando-o a cada dia mais estar integrado na empresa.

$\mathrm{Na}$ pergunta "a empresa oferece oportunidades de crescimento profissional"? 61\% responderam que sim. Uma das fontes de motivação é sabermos que teremos um crescimento na organização, pois os mesmos não pensarão duas vezes para mudar de empresa, onde outra lhe oferecerá um mínimo de oportunidade de conhecimento.

Gráfico 4 - A empresa oferece oportunidades de crescimento profissional?

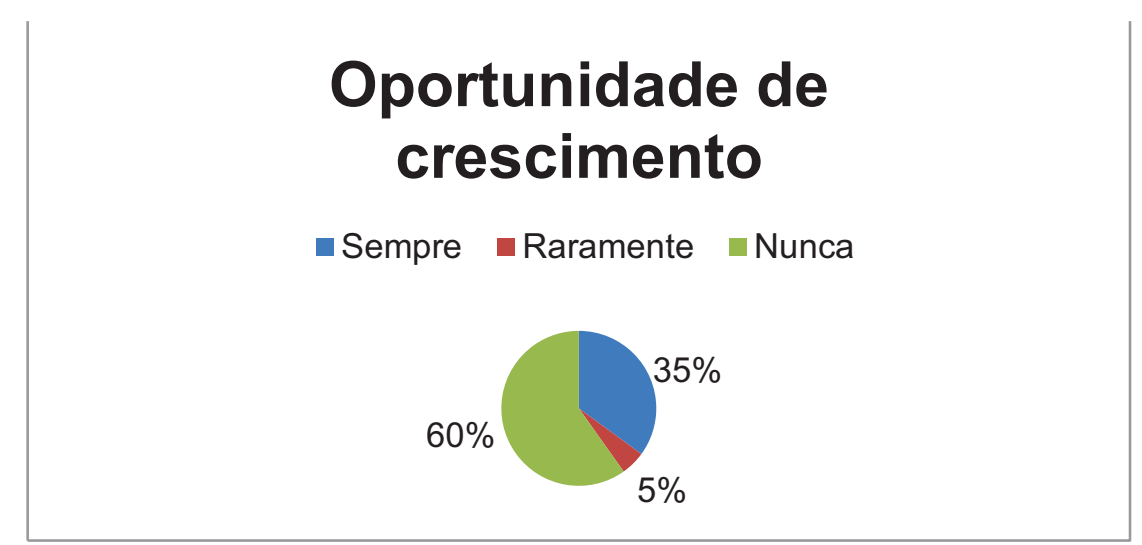

Fonte: os autores 
Conhecimento é algo que ninguém pode nos roubar. Quando somos motivados por aprendizado, tudo se torna um desafio. A sede de aprender, se auto desafiar, é uma fonte de motivação que persiste em se renovar a cada dia, assim, como podemos observar no gráfico abaixo é possível compreender que $76 \%$ dos entrevistados afirmam que o aprendizado é o que realmente os motiva.

Gráfico 5 - Trabalhar nesta empresa/organização é um (a)

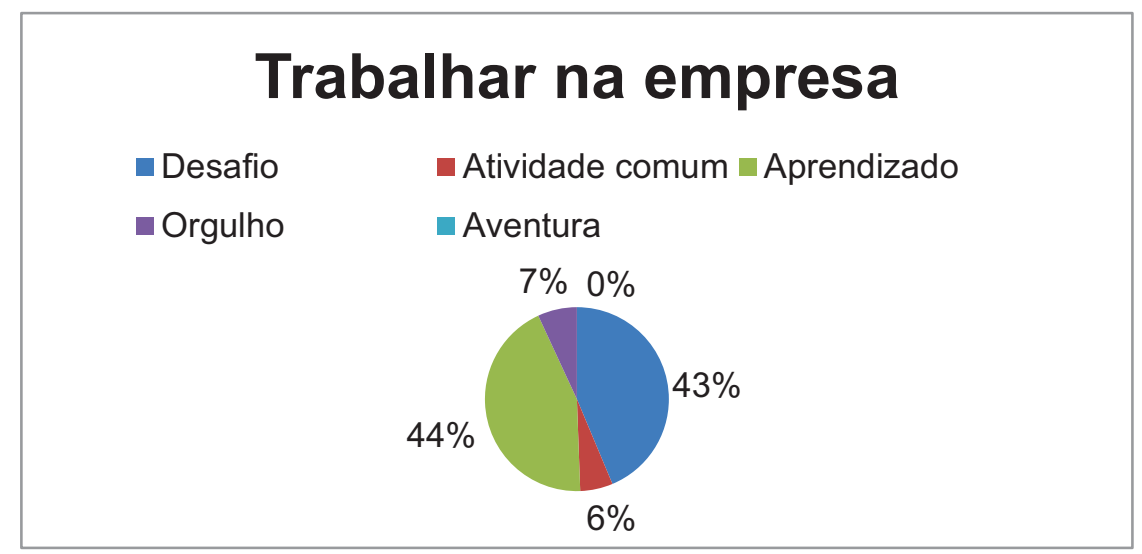

Fonte: os autores

Um dos fatores que incomodam os colaboradores é a falta de reconhecimento. No gráfico abaixo 68\% confirmam que na empresa pesquisada os colaboradores se sentem bastante reconhecidos pela empresa. Sentir-se útil e parte da empresa é o que todos querem, sendo valorizados por cada esforço, por cada objetivo alcançado. Agindo dessa forma o empregador demonstra aos seus colaboradores o quanto o capital humano é importante. A queda de produtividade é maior em ambientes organizacionais onde os empregados não se sentem valorizados. Quem produz em uma empresa onde não é reconhecido?

Gráfico 6 - Você se sente reconhecido pela empresa/organização?

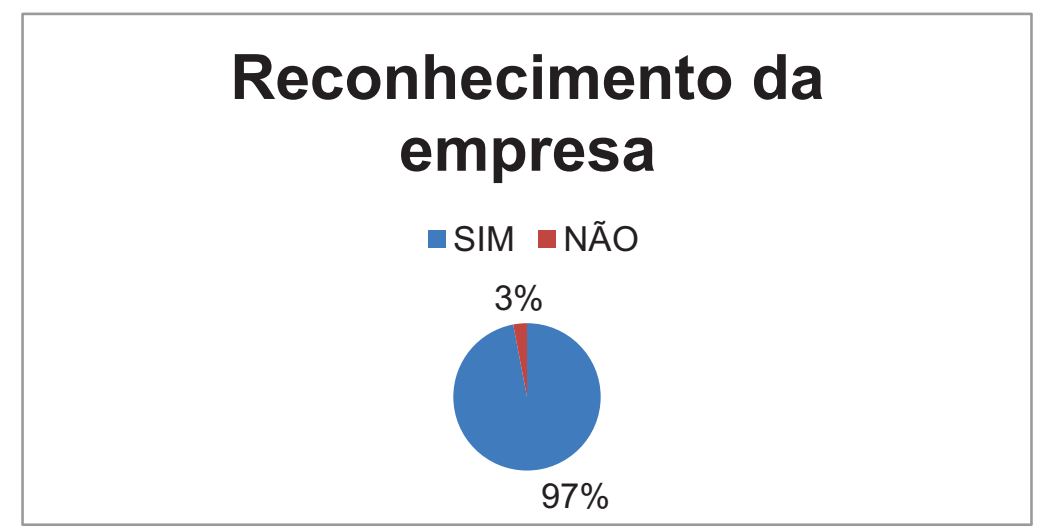

Fonte: os autores 
O gráfico abaixo demonstra que os colaboradores responderam que $91 \%$ se sentem bastante motivados. A motivação é algo interno, mas o ambiente externo ajuda, proporcionando fontes de motivação, um novo cargo, uma troca de serviços, um novo desafio, algo que satisfaça as necessidades e que rompe a barreira de equilíbrio interno.

Gráfico 7 - Qual o seu grau de motivação?

\section{Grau de motivação}

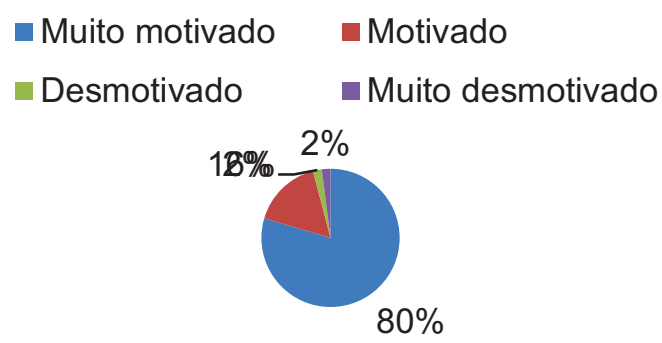

\section{Fonte: os autores}

A motivação diferencia de uma pessoa para outra. O que motiva e impulsiona todos os dias não são as mesmas coisas que movem o colega de trabalho. Por sermos indivíduos diferentes, os gostos e as preferências mudam de pessoa para pessoa. O resultado do gráfico abaixo corresponde à pergunta: "o que lhe motiva"? O resultado nos mostra que evoluir na carreira se encontra bem a frente de dinheiro. Isso só mostra que os profissionais estão cada dia mais pensando no futuro, sabendo que cada esforço ou objetivo alcançado será reconhecido.

Gráfico 8 - O que lhe motiva a trabalhar?

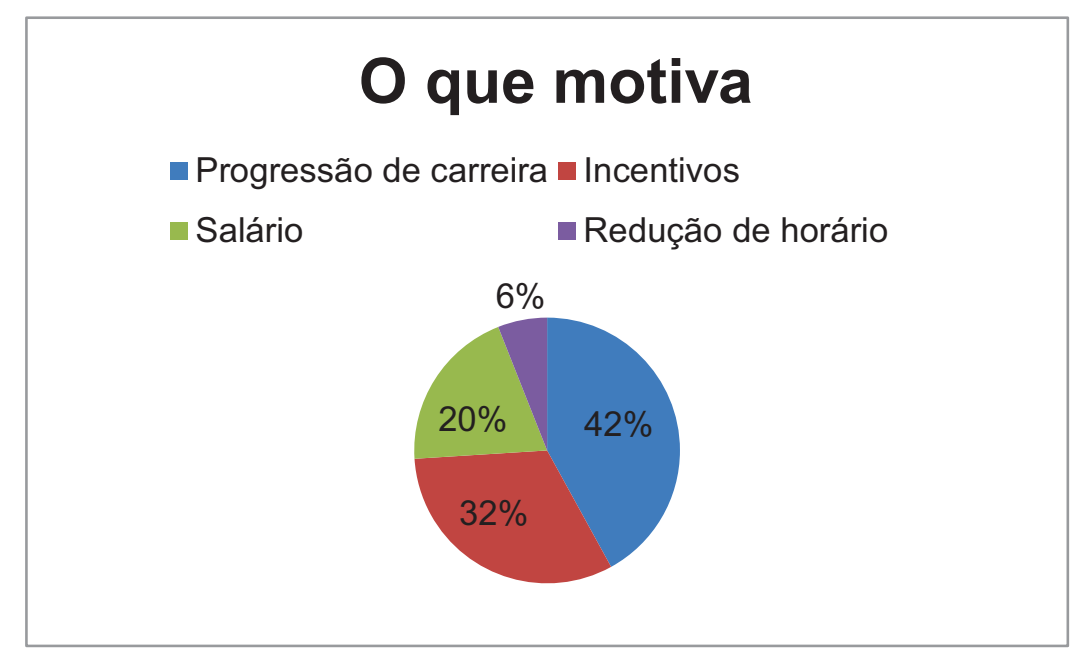

Fonte: os autores 
Toda empresa deve estar atenta aos seus colaboradores. O que fazem para produzir mais? Quais as expectativas que eles têm mediante a empresa? A instituição busca atender essas expectativas a cada dia? A empresa visa cada dia mais entender e buscar um clima organizacional produtivo?

Na pergunta "a empresa dá a devida atenção à motivação e à satisfação dos funcionários" 96\% afirmam que sim, a empresa mostra plena ciência de como anda a satisfação de seus colaboradores. Assim sendo, a mesma pode cobrar mais empenho. Esse questionário de desempenho deve ser um trabalho exclusivo do RH que, junto com os gestores, procuram solucionar essas questões de extrema importância à satisfação dos colaboradores.

Gráfico 9 - A empresa que você trabalha dá a devida atenção à motivação e satisfação dos seus funcionários?

\section{Atenção da empresa com a motivação e satisfação do colaborador}

$\because \mathrm{SIM} \backsim \mathrm{NÃO}$

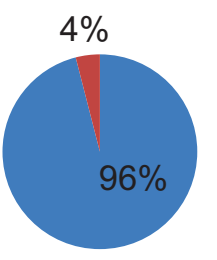

Fonte: os autores

Quando foi perguntado ao colaborador o grau de importância motivacional, em primeiro lugar, com a maior porcentagem, surgiu o plano de cargos e salários com 32\%. Existem algumas empresas que já reconhecem que esse fator é muito importante, pois muitos de seus colaboradores se sentem satisfeitos em saber que a empresa reconhece o seu profissional. $\mathrm{O}$ objetivo de se ter plano de cargos e salários na empresa é classificar o funcionário de acordo com suas habilidades, assim valorizando seus esforços de melhoria.

\section{CONSIDERAÇÕES FINAIS}

$\mathrm{Na}$ realização desse trabalho, por meio desta pesquisa, foi possível compreender que a motivação é um dos assuntos com múltiplas visões. 
Os colaboradores são motivados, acima de tudo, pela qualidade de seu trabalho e pelas relações que lhes dão suporte. Quanto mais motivado o ser humano estiver, maior será o conjunto de capacitações transformadas em ação prática. Qualquer instituição pode ter uma consistente e lucrativa ação na criação de motivos que levam pessoas a aumentar o padrão, a qualidade e a quantidade de suas ações.

Mediante o estudo realizado foi possível entender que a empresa mantém, na medida do possível, os padrões para atender as necessidades dos colaboradores, pois para estes os principais fatores motivacionais que predominam são o reconhecimento e o plano de cargos e salários.

Atualmente, é fundamental que as empresas busquem formar líderes e integrar pessoas com este perfil a seus quadros, o que demonstra a relevância do presente tema. Com base no que foi apresentado, é correto afirmar, então, que o líder motiva a equipe e deve estar preparado para estimular seus integrantes em relação ao trabalho, visando a torná-los mais efetivos em relação aos objetivos da empresa.

Percebemos que quando um colaborador está motivado em seu ambiente de trabalho, tudo flui melhor, tanto no trabalho que ele desempenha quanto para ajudar o colega na função. A empresa deve dar um pouco mais de atenção ao colaborador. Essa atenção surge não só da parte dos lideres, mas também dos colaboradores entre si.

\section{REFERÊNCIAS}

CHIAVENATO, I. Introdução à teoria geral da administração: uma visão abrangente da moderna administração das organizações. 7. ed. Rio de Janeiro: Campus, 2004.

CHIAVENATO, I. Introdução à teoria geral da administração. São Paulo: Elsevier, 2003.

DUTRA, Joel S. Gestão de pessoas: modelo, processos, tendências e perspectivas. 7 . reimp. São Paulo: Atlas, 2009.

FERREIRA, Paulo P. Administração de pessoas. 2. ed. São Paulo: Atlas, 2001.

LOPES, Michelle; OLIVEIRA, Waleska; QUEIROZ, André. Motivação e Liderança Dentro das Empresas. $2017 . \quad$ Disponível Em: https://revista.pgsskroton.com/index.php/rcger/article/view/3971 . Acesso em: 10 maio 2021.

MAXIMIANO, Antônio César Amaru. Introdução à Administração. 5. ed. São Paulo: Atlas, 2010.

RIBEIRO, Antonio L. Gestão de pessoas. São Paulo: Saraiva, 2006. 
SILVA, G. Motivação: uma análise do comportamento do indivíduo na organização. Administradores. Disponível em: http://www.administradores.com.br/artigos/tecnologia/motivacao-uma-analise-docomportamento-do-individuo-dentro-das-organizacoes/57558/. Acesso em: 12 dez. 2020.

SOUSA, K. Recompensas organizacionais. Psicologado Artigos. Disponível em: https://psicologado.com/atuacao/psicologia-organizacional/recompensas-organizacionais. Acesso em: 15 dez. 2020.

VROOM, Victor H. Gestão de pessoas, não de pessoal. Rio de Janeiro: Elsevier, 1997. 